\title{
Protez temizleme solüsyonlarının hassas bağlantılı protezlerde matris tutuculuğuna etkisinin değerlendirilmesi
}

\author{
Umut Cakan ${ }^{1}$, Tuba Yılmaz ${ }^{2}$, Haluk Barış Kara ${ }^{1}$
}

\section{Evaluation of the effect of denture cleansers on matrix retention of precision attachment partial dentures}

Background: The aim of this study was to evaluate the effect of the various denture cleansers on retention of plastic precision attachment matrices in partial removable dentures.

Methods: One control and four test groups (10 pairs each) of matrices (Bredent VKS-SG) were soaked for the equivalent of 6 months of clinical use in the following solutions: Water (control), Corega, Protefix, 5\% Sodium hypochlorite (NaOCL, 1:10 diluted) and Listerine mouthwash. A universal testing machine set at a crosshead speed of $0,5 \mathrm{~cm} / \mathrm{min}$ was used to perform one pull. The peak load-to-dislodgement was recorded to reflect changes in the retention of the matrices after soaking. Data were analyzed by one-way ANOVA followed by Tukey's Honestly Significant Difference test. A $p<0.05$ was considered significant.

Results: Denture cleansing solutions tested significantly affected the retentive values of matrices $(p<0.01)$. NaOCl increased the retentive values of the matrices $(19,02 \pm 2,26$ $\mathrm{N})$ when compared to the control group $(15,67 \pm 2,75 \mathrm{~N})$. There was no significant difference in the retentive values of attachments soaked in Corega, Protefix or Listerine when compared to the control group.

Conclusion: The use of $\mathrm{NaOCl}$ may be recommended for cleaning of the removable partial dentures with precision attachments because of its increasing effect on the retentive values of the matrices within the limitations of the test conditions.

\section{KEY WORDS}

Denture, hygiene, precision attachment, retention
Hareketli bölümlü protez (HBP), bir veya birden çok diş kaybı halinde meydana gelen bölümlü dişsizliği ve sert ve yumuşak doku kayıplarını restore eden, diş ve mukoza destekli protezlerdir (Ulusoy 2003). Bu protezler ile özellikle posterior dişlerin kaybında, çiğneme etkinliğinin yeniden kazandırılması, anterior diş eksikliklerinde estetiğin ve fonasyonun düzeltilmesi ve mevcut dişlerin ve dokuların sağlık ve devamlılıklarının korunması amaçlanmaktadır. HBP'de, protezin dokulardan ayrılmasını ve hareket etmesini önlemek için gerekli olan tutuculuk dişlere bağlanan kroşeler ile sağlanır. Ancak anterior bölgede tutuculuğun kroşe yerine hassas bağlantı ile sağlanması estetiğe önemli ölçüde katkı sağlar (Preiskel 1979). Hassas bağlantılı HBP'nin, fonksiyonel kuvvetler karşısında dikey ve yatay yönde yer değiştirmeye karşı daha dirençli olduğu bildirilmiştir (Burns ve ark 1990). Buna bağlı olarak hassas bağlantılı HBP'nin, geleneksel kroşe tutuculu HBP'ye göre, kuvvetlerin dengeli dağılımı ve estetik yönünden daha avantajlı oldukları kabul edilebilir (Mensor 1990).

Hassas bağlantılar kron içi ve kron dışı olmak üzere iki grupta toplanabilirler (Deniz ve Özkan 2012). Kron dışı hassas bağlantılarda patrisin bir kısmı veya tümü kuron konturları dışında yer alır. Matris ise protez iskeletine tespit edilen metal bir yuva ile buna sıkıca uyan plastik bir parçadan oluşan tutucudur (Preiskel 1979). Bu tür bağlantılardan elde edilen direkt tutuculuk alt ve üst yapı arasındaki sürtünmeden kaynaklanan primer tutuculuktur (Hedzelek ve ark 2011).

\footnotetext{
1 İstanbul Medipol Üniversitesi Diş Hekimliği Fakültesi Protetik Diş Tedavisi Anabilim Dalı, İstanbul, Türkiye

${ }^{2}$ Selçuk Üniversitesi Diş Hekimliği Fakültesi Protetik Diş Tedavisi Anabilim Dalı, Konya, Türkiye
} 
Hareketli bölümlü protezlerin kullanımı süresince, dişlerin yanı sıra protezi destekleyen sert ve yumuşak dokuların sağlığının ve devamlılığının korunması de önem taşır (Peracini ve ark 2010). Protez üzerinde biriken bakteri plağının, gıda artıklarının ve kalkulusun protez stomatitinin patogenezisinde önemli bir etken olduğu ve doku sağlığını olumsuz etkilediği bildirilmiştir (Paranhos ve ark 2007). Protez üzerinde biriken plakların uzaklaştırılmasında mekanik temizlemenin (fırçalama, ultrasonik temizleme) yanı sıra özellikle motor koordinasyonu zayıflamış yaşlı hastalarda temizleme işlemini kolaylaştırmak amacıyla kimyasal temizleme yöntemleri de yaygın olarak kullanılmaktadır (Mc Cabe ve ark 1995, Gornitsky ve ark 2002). Kimyasal temizleme yönteminde protezler genel olarak ticari formda alkalin peroksitler (sodyum perborat, potasyum monopersülfat, sodyum perkarbonat), hipokloritler (sodyum ile birlikte trisodyum fosfat), seyreltik asitler (hidroklorik, fosforik asit), dezenfektanlar (klorheksidin gluteraldehit, salisilat) ve enzimler içeren solüsyonlara daldırılır (Nalbant ve ark 1994).

Temizleme ajanlarında aranılan önemli iki özellik; etki mekanizmalarına bağlı olarak protez üzerinde biriken plak ve artıkları etkili bir şekilde temizlemesi ve protez kaide materyali olarak kullanılan akriliğin fiziksel özelliklerini olumsuz bir şekilde etkilememesidir. Hassas bağlantılarda kullanılan plastik parçalar poliamidden üretilirler (Varghese ve ark 2007).

Protez temizliğinde sıklıkla kullanılan sodyum hipokloritin ( $\mathrm{NaOCl})$, poliamidin mekanik özelliklerini olumsuz etkilediği gösterilmiştir (Cornelius ve ark 2002). Literatürde, protez temizleyicilerin temizleme ve bakterisid kapasiteleri ile protezin akrilik ve metal bölümleri üzerinde oluşturdukları etkileri inceleyen çok sayıda araştırma mevcut olmasına karşın bu ajanların hassas bağlantıların tutuculuğuna olan etkileri hakkında kısıtlı sayıda araştırma mevcuttur.

$\mathrm{Bu}$ çalışmanın amacı, hareketli protezlerin temizlenmesinde kullanılan ağız gargarasının ve üç değişik protez temizleme ajanının, plastik hassas bağlantı matrislerinin tutuculuğuna etkisini incelemektir.

\section{GEREÇ ve YÖNTEM}

Hassas bağlantılı HBP'leri taklit etmek amacıyla, kron dışı hassas bağlantı elemanı (VKS-SG, Bredent, Senden, Almanya), 20 × 8 × 8 ebadında hazırlanan mum (Modelasyon mumu 725070, Erkodent, Pfalzgrafenweiler, Almanya) prizmaya paralelometre kullanılarak bağlandı ve geleneksel yöntemler ile Ni$\mathrm{Cr}$ alaşımından (MoguCera N, Scheftner, Mainz, Almanya) dökümü yapıldı. Hassas bağlantının plastik matrisi, patris üzerine takılarak HBP'nin iskelet modelasyonu bitirildi ve aynı yöntemle döküme alındı. Daha sonra HBP'yi taklit eden test düzeneği paralelometre kullanılarak akrilik rezin (Meliodent, Heraeus Kulzer, Hanau, Almanya) blok içine gömüldü (Şekil 1).

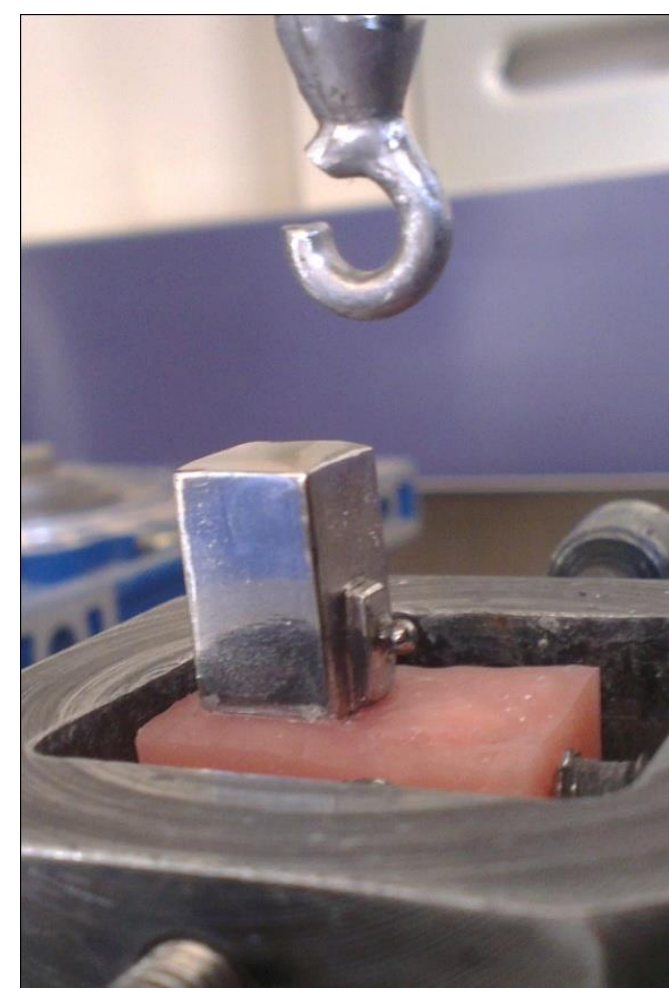

Şekil 1.

Kron dışı hassas bağlantı

Çalışmamızda her biri 10 adet plastik matris içeren, bir kontrol ve dört test grubu bulunmaktadır. Kullanılan temizleyici ajanların isimleri, üretici firmaları ve içerikleri Tablo 1'de belirtilmiştir.

Grup 1; Kontrol grubu, herhangi bir temizleme ajanı ilave edilmemiş şebeke suyu.

Grup 2; Corega Tabs, temizleyici solüsyon, üreticinin önerileri doğrultusunda $200 \mathrm{ml}$ şebeke suyuna 1 adet efervesan tablet atılarak hazırlanmıştır.

Grup 3; \%5'lik $\mathrm{NaOCl}, 1: 10$ oranında seyreltilerek kullanılmıştır.

Grup 4; Protefix, temizleyici solüsyon, üreticinin önerileri doğrultusunda $200 \mathrm{ml}$ şebeke suyuna 1 adet efervesan tablet atılarak hazırlanmıştır.

Grup 5; Listerine, ağız gargarası, su ilave edilmeden $30 \mathrm{ml}$, kullanılmıştır. 
Tablo 1.

Çalışmada kullanılan malzemeler ve özellikleri

\begin{tabular}{|c|c|c|}
\hline Ürün adı & Üretici & İçerik \\
\hline $\begin{array}{l}\text { Corega } \\
\text { Tabs }\end{array}$ & $\begin{array}{l}\text { Glaxo Smith } \\
\text { Kline, Brentford, } \\
\text { İngiltere }\end{array}$ & $\begin{array}{l}\text { Sodyum karbonat, Sodyum } \\
\text { perborat, Sodyum bikarbonat, } \\
\text { Sitrik asit, Potasyum } \\
\text { monopersülfat bileşiği, Sodyum } \\
\text { benzoat, Polietilen glikol } 8000 \\
\text { NF, VP/VA S } 630 \text { Kopolimer, } \\
\text { Sodyum loril sülfoasetat, } \\
\text { Proteollitik enzim, Nane yağı. }\end{array}$ \\
\hline Protefix & $\begin{array}{l}\text { Queisser Pharma } \\
\text { GmbH \& Co, } \\
\text { Flensburg, } \\
\text { Almanya }\end{array}$ & $\begin{array}{l}\text { Sodyum perborat ve enzim, } \\
\text { Sodyum bikarbonat, Potasyum } \\
\text { karoat, Sodyum perborat, Sitrik } \\
\text { asit, Sodyum loril sülfat, Cl } \\
\text { 73105, Aroma. }\end{array}$ \\
\hline $\begin{array}{l}\text { Listerine }{ }^{\circledR} \\
\text { Total Care } \\
\text { Fresh Mint }\end{array}$ & $\begin{array}{l}\text { Johnson \& } \\
\text { Johnson, ABD }\end{array}$ & $\begin{array}{l}\text { Su, Alkol, Sorbitol, Aroma, } \\
\text { Poloxamer 407, Benzoik asit, } \\
\text { Çinko klorid, Okaliptol, Metil, } \\
\text { salisilat, Sodyum sakkarin, } \\
\text { Timol, Mentol, Sodyum benzoat, } \\
\text { Sodyum florid, Sukraloz, Benzil } \\
\text { alkol, Cl 16035, Cl 42090, } \\
\text { Sodyum florür (100ppm F). }\end{array}$ \\
\hline Wizard & $\begin{array}{l}\text { Rehber Kimya, } \\
\text { İstanbul, Türkiye }\end{array}$ & $\% 5 \mathrm{NaOCl}$ \\
\hline
\end{tabular}

Her grup için plastik matrisler su ve solüsyon içeren protez kaplarına daldırıldı ve üzerlerine ince tel bir ağ konularak solüsyon ile tam temas etmeleri sağlandı. Protez temizleme tableti üreticilerinin önerisi doğrultusunda günlük bekletme süresi $15 \mathrm{dk}$. olarak belirlendi. Her 15 dakikada bir tüm test solüsyonları değiştirildi. Altı aylık toplam uygulama süresine paralellik kurmak amacı ile her gün 5 saat çalışılarak bu işlem 9 gün boyunca tekrarlandı. Deney sürelerinin dışında örnekler distile suda bekletildi ve her deney öncesinde tüm örnekler akar su altında yıkandı. Kontrol grubu ise sadece şebeke suyunda bekletildi. Tüm örnekler sıra ile matris yerleştirici alet kullanılarak test düzeneğine takıldı ve üniversal test cihazında (TSTM 02500, Elista Ltd Şti, İstanbul, Türkiye) 0,5 $\mathrm{cm} / \mathrm{dk}$ kafa hareket hızı ile çekme testine tabi tutuldu (Şekil 2). Ayrıma anındaki değer Newton (N) olarak kaydedildi.

\section{İstatistiksel analiz}

İstatistiksel analizler için IBM SPSS Statistics 22 (IBM SPSS, Türkiye) programı kullanıldı. Çalışma verileri değerlendirilirken parametrelerin normal dağllıma uygunluğu Shapiro Wilks testi ile değerlendirildi ve parametrelerin normal dağılıma uygun olduğu saptandı. Parametrelerin gruplar arası karşılaştırmalarında tek yönlü varyans analizi ve farklılığa neden olan grubun tespitinde Tukey HSD testi kullanıldı. Anlamlıık $\mathrm{p}<0.05$ düzeyinde değerlendirildi.

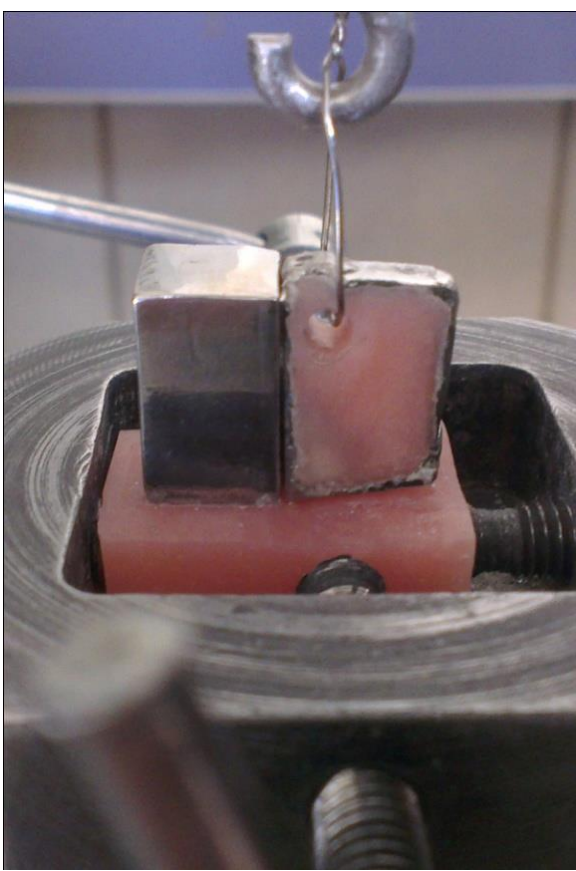

Şekil 2.

Test düzeneği

\section{BULGULAR}

Su ve dört farklı solüsyon uygulanmış örneklerin tutuculuk değerleri Tablo 2'de görülmektedir. Solüsyon gruplarına göre tutuculuk ortalamaları arasında istatistiksel olarak anlamlı farklılık bulunmuştur $(p<0.01) . \quad \mathrm{NaOCl}$ solüsyonunun tutuculuk ortalaması, Su (p:0.015), Corega (p:0.005), Protefix (p:0.015) ve Listerine (p:0.005) solüsyonlarının ortalamalarından istatistiksel olarak anlamlı düzeyde yüksek bulunmuştur $(p<0.01)$ (Tablo 2 ve Şekil 3). Diğer solüsyon grupları arasında istatistiksel olarak anlamlı bir farklıık bulunmamıştır $(p>0.05)$.

Tablo 2.

\section{Beş farklı solüsyona göre tutuculuğun değerlendirilmesi}

\begin{tabular}{|ll|} 
& $\begin{array}{l}\text { Tutuculuk } \\
\text { Ort } \pm S S\end{array}$ \\
\hline Grup 1: Su & $15,67 \pm 2,75^{\mathrm{a}}$ \\
\hline Grup 2: Corega & $15,12 \pm 3,48^{\mathrm{a}}$ \\
\hline Grup 3: NaOCl & $19,02 \pm 2,26^{\mathrm{b}}$ \\
\hline Grup 4: Protefix & $15,66 \pm 2,94^{\mathrm{a}}$ \\
\hline Grup 5: Listerine & $15,19 \pm 3,10^{\mathrm{a}}$ \\
\hline$P$ & $0,002^{* *}$ \\
\hline
\end{tabular}

Tek yönlü ANOVA $\quad * * p<0.01$

Aynı harfler arasında istatistiksel olarak fark yoktur. 


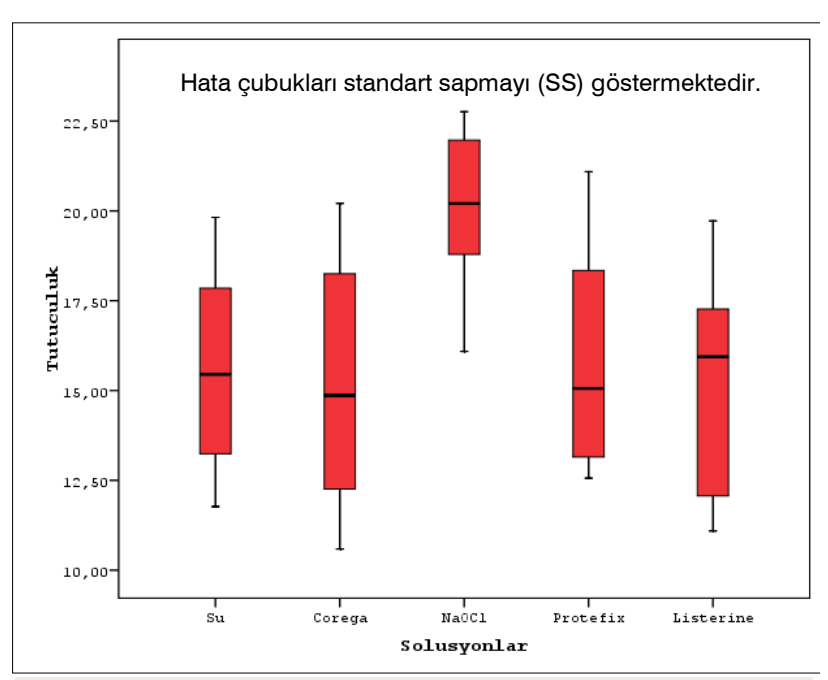

Şekil 3.

Solüsyonlara göre ortalama tutuculuk değerleri

\section{TARTIŞMA}

$\mathrm{Bu}$ çalışmada hassas bağlantı sisteminin plastik matrisleri farklı temizleme solüsyonları içine daldırımış ve tutuculuklarında meydana gelen değişiklikler incelenmiştir. Sonuçlar, farklı temizleme solüsyonlarının öngörülen 6 aylık kullanım sonunda matrislerin tutuculuğunu etkilediğini göstermiştir. Özelikle seyreltilmiş \%5'lik $\mathrm{NaOCl}$ içinde bekletilen matrislerin tutuculuk değerleri diğer gruplardan istatistiksel olarak anlamlı ölçüde yüksektir (Tablo 1). Su, Corega, Protefix ve Listerine ise birbirine yakın tutuculuk değerleri göstermiştir. Bu sonuç temizleme solüsyonlarının Hader klipslerin tutuculuğuna etkisini inceleyen çalışmanın sonuçları ile örtüşmektedir. Günde 15 dakika süre ile $\% 5,25$ 'lik $\mathrm{NaOCl}$ içinde bekletilen Hader klipslerde yüksek tutuculuk değeri bildirilmiştir (Varghese 2007). Klipslerin üretiminde poliamid (naylon) kullanılmaktadır. Bu sonuç NaOCl'nin poliamid klipslerin sertliğini artırması ve dolayısı ile tutuculuğun da artması ile ilişkilendirilmiştir (Varghese 2007). Öte yandan NaOCl'nin, poliamidin yüzey morfolojisinde porözite ve mikroçatlaklara yol açtığı bildirilmiştir (Cornelius 2002). Protez temizleyici ajanların kullanımında üretici firmalar, genellikle protezlerin temizleyici solüsyonda 10 ila 15 dakika bekletilmesini önermektedirler. Protez temizleyicisi kullanan hastalar, protezlerini bir gece boyunca solüsyonda beklettiklerini söylemektedirler. Günlük 8 saatlik kullanımda \%6,15'lik NaOCl'nin Locator ataçmanların tutuculuğunu azalttığı gösterilmiştir. Aynı çalışmada, sonuçlarımız ile paralel olarak su, alkalin peroksit tablet temizleyiciler ve Listerine gargaranın tutuculuk değerlerine etkileri arasında istatistiksel olarak anlamlı fark bulunmamıştır (You 2011). Bu bağlamda günlük 15 dakikayı aşan daldırma sürelerinin matrislerin yapısında meydana getireceği değişikliklerin incelenmesi farklı sonuçlar ortaya koyabilir.

$\mathrm{NaOCl}$ solüsyonlarının kokusu birçok hastanın hoşuna gitmemektedir ancak nispeten ucuz ve kolay ulaşılabilir olması da bir avantaj olabilir (Felipucci 2011). Barnabe ve arkadaşları, \%5'lik NaOCl'nin protez yüzeyinde $C$ albicans ve $S$ mutans 'ı azalttığını ve protezde biofilm oluşumunu sınırladığını bildirmişlerdir (Barnabe ve ark 2004). Hipokloritlerin rutin kullanımda metal komponenti olan protezlerde kararma ve korozyona neden oldukları bildirilmiştir (Türköz 1988).

Protez temizliği ve dezenfeksiyonu için ağız gargaralarının kullanımı yaygın bir uygulama olmayabilir. Ancak ilgili literatür incelendiğinde bu ürünlerin protez temizliğinde etkinliğini inceleyen çalışmalar mevcuttur (Schwartz ve ark 1988, Webb ve ark 1998, Al Habashneh ve ark 2014). Listerine bakteri hücre duvarında değişikliğe yol açarak etki gösterir.. İçeriğinde \%0.064 oranında timol, \%0.092 okaliptol ve $\% 0.042$ oranında metol gibi fenol türevi esansiyel yağlar ile birlikte metil salisilat bulunur (Al Habashneh ve ark 2014). Çalışmamızda Listerine uygulanan matrislerin tutuculuğu, kontrol grubuna göre daha azdır. Ancak aralarındaki fark istatistiksel olarak anlamlı değildir. Bizim araştırmamızdan farklı olarak, Listerine'in pembe Locator ataçmanların tutuculuğunu arttırdığı bildirilmiştir (You 2011). Sonuçlarımız arasındaki uyumsuzluk, farklı uygulama süresi ve farklı tutucu ataçman materyalinden kaynaklanabilir.

Tablet ya da toz halinde satışa sunulan alkalin peroksitler su içerisinde çözününce içeriğindeki perborat reaksiyona girerek peroksit çözeltisi oluşur ve oksijen açığa çıkar. Açığa çıkan oksijen mekanik bir etkiyle birikintileri yerinden sökerek protezden uzaklaştırır (Nikawa ve ark 1999). Bu malzemelerin tutucu ataçmanlara etkisi üzerine az sayıda araştırma mevcuttur (You 2011 ve Nugyen 2010). Çalışmamızda, alkalin peroksit temizleme tabletleri matrislerin tutuculuğunu kontrol grubuna göre azaltmıştır ancak Corega ve Protefix arasında anlamlı fark bulunmamıştır. Ancak 6 aydan daha uzun kullanım süresi ve protezin takıp çıkarma sıklığı farklı sonuçlar ortaya çıkarabilir.

In vitro olarak gerçekleştirilen bu çalışmanın koşulları, in vitro koşullardan farklılık göstermektedir. Çalışmamızda tek bir çekme testi uygulanmıştır. Oysa hastalar HBP'yi temizleyici solüsyona koymadan önce gün içinde defalarca takıp çıkarabilirler ve protezler günlük 15 dakika süre ile solüsyona maruz kalmaktadır. Ancak çalışmamızda toplam altı aylık daldırma süresinin etkisini değerlendirmek amacı ile matrisler uzun süre ara 
vermeksizin temizleyici solüsyon içinde bekletilmişlerdir ve ISı ve basınç altında çiğneme siklusunun olası etkileri incelenmemiştir. Bu koşulların birlikte değerlendirileceği ileri çalışmalara intiyaç vardır.

\section{SONUÇLAR}

Bu çalışmanın koşulları dahilinde;

1) Su, Corega, Protefix ve Listerine, seçilen hassas bağlantı matrisinin tutuculuğunu etkilemeyebilir.

2) \%5'lik $\mathrm{NaOCl}$ matrislerin tutuculuğunu anlamlı olarak arttırabilir ancak bu sonuç NaOCL'nin hassas bağlantılı protezlerin temizliği için tek ve en uygun malzeme olduğu önermesini doğurmaz.
Protez temizleme solüsyonlarının hassas bağlantılı protezlerde matris tutuculuğuna etkisinin değerlendirilmesi

Amaç: Bu çalışmanın amacı, hareketli protezlerin temizlenmesinde kullanılan ağız gargarasının ve üç değişik protez temizleme ajanının, plastik hassas bağlantı matrislerinin tutuculuğuna etkisini incelemektir.

Gereç ve Yöntemler: Çalışmamızda bir kontrol ve dört test grubunda $(n=10)$ olmak üzere örnekler toplam 6 aylık kullanım süresine eşit olacak şekilde, su (kontrol), Corega, Protefix, \%5'lik $\mathrm{NaOCl}$ ve Listerine gargara içinde bekletildi. Tüm örnekler sıra ile matris yerleştirici alet kullanılarak test düzeneğine yerleştirildi ve üniversal test cihazında $0,5 \mathrm{~cm} / \mathrm{dk}$ kafa hızı ile çekme testine tabi tutuldu. Parametrelerin gruplar arası karşılaştırmalarında tek yönlü varyans analizi ve farklılığa neden olan grubun tespitinde Tukey HSD testi kullanıldı. Anlamlılı $p<0.05$ düzeyinde değerlendirildi.

Bulgular: Solüsyon gruplarına göre tutuculuk ortalamaları arasında istatistiksel olarak anlamlı farklılık bulunmuştur $(p<0.01) . \quad \mathrm{NaOCl}$ solüsyonunun tutuculuk ortalaması $\mathrm{Su}$ (p:0.015), Corega (p:0.005), Protefix (p:0.015) ve Listerine (p:0.005) solüsyonlarının ortalamalarından istatistiksel olarak anlamlı düzeyde yüksek bulunmuştur $(p<0.01)$. Diğer solüsyon grupları arasında istatistiksel olarak anlamlı bir farklılık bulunmamıştır ( $p>0.05)$.

Sonuç: Test koşulları dahilinde matrislerin tutuculuğunda artışa yol açtığı için hassas bağlantılı hareketli protezlerin temizliğinde $\mathrm{NaOCl}$ kullanımı önerilebilir.

\section{ANAHTAR KELIMELER}

Hassas bağlantı, hijyen, protez, retansiyon 


\section{KAYNAKLAR}

Al Habashneh R, Qubain TG, Alsalman W, Khader $Y, 2014$. The Effect of Listerine Mouthwash on Dental Plaque, Gingival Inflammation and C - reactive protein (CRP). Dentistry, 4:191.

Barnabe W, de Mendonca Neto T, Pimenta FC, Pegoraro LF, Scolaro JM, 2004. Efficacy of sodium hypochlorite and coconut soap used as disinfecting agents in the reduction of denture stomatitis, Streptococcus mutans and Candida albicans. J Oral Rehabil, 31:453-9.

Burns DR, Ward JE, 1990. Review of attachments for removable partial denture design: 1. Classification and selection. Int J Prosthodont, 3:98-102.

Cornelius RM, McClung WG, Barre P, 2002. Effect of reuse and bleach/formaldehyde reprocessing on polysulfone and polyamide hemodialyzers. ASAIO J, 48:300-11.

Deniz AD, Özkan YK, 2012. Hassas bağlantılı protezler ve uygulanmasında dikkat edilmesi gereken kriterler. Atatürk Üniv Diş Hek Fak Derg, Supplement 6: $132-41$.

Felipucci DN, Davi LR, Paranhos HF, Bezzon OL, Silva RF, Pagnano VO, 2011. Effect of different cleansers on the surface removable partial denture. Braz Dent J, 22:392-7.

Gornitsky M, Paradis I, Landaverde G, Malo AM, Velly AM, 2002. A clinical and microbiological evaluation of denture cleansers for geriatric patients in long-term care institutions. J Can Dent Assoc, 68:39-45.

Hedzelek W, Rzatowski S, Czarnecka B. Evaluation of the retentive characteristics of semi-precision extracoronal attachments. J Oral Rehabil 2011 , 38:462-8.

Mc Cabe JF, Murray ID, Kelly PJ, 1995. The efficacy of denture cleansers. Eur J Prosthodont Restor Dent, 3:203-7.

Mensor MC, 1990. Removable partial overdentures with mechanical (precision) attachments. Dent Clin North Am, 34:669-81.

Nalbant D, Demirköprülü H, Karacaer Ö, Kocabalkan E, 1994. Çeşitli protez temizleyici ajanların akrilik kaide materyalinin yüzey sertliği ve yatay dayanıklığına etkisi. Diş Hek Fak Der, Cilt XI, Sayı 1, Sayfa 73-8.

Nikawa $H$, Hamada $T$, Yamashiro $H$, Kumagai $H$, 1999. A review of in vitro and in vivo methods to evaluate the efficacy of denture cleansers. Int $J$ Prosthodont, 12:153-9
Nguyen CT, Masri R, Driscoll CF, Romberg E, 2010. The effect of denture cleansing solutions on the retention of pink Locator attachments: an in vitro study. J Prosthodont, 19:226-30.

Paranhos HF, Silva-Lovato CH, Souza RF, Cruz PC, Freitas KM, Peracini A, 2007. Effects of mechanical and chemical methods on denture biofilm accumulation. J Oral Rehabil, 34:606-12.

Peracini A, Andrade IM, Paranhos H de F, Silva $\mathrm{CH}$, de Souza RF, 2010. Behavior and hygiene habits of complete denture wearers. Braz Dent J, 21:247-52.

Preiskel HW, 1979. Precision Attachments in Dentistry 3 ed, St Louis; CV Mosby

Schwartz IS, Young JM, Berrong JM, 1988. The effect of Listerine Antiseptic on denture microbial flora and denture stomatitis. Int J Prosthodont, 1:153-8.

Türköz Y, 1988. Kimyasal protez temizleyicilerin protez metalleri üzerindeki zararlı etkileri. A Ü Diş Hek Fak Derg, 15: 143-8.

Ulusoy M, Aydın AK,2003. Diş Hekimliğinde Hareketli Bölümlü Protezler Cilt I, p. 273-483.

Webb BC, Thomas CJ, Willcox MDP, Harty DWS , Knox KW, 1998. Candida-associated denture stomatitis. Aetiology and management: A review. Part 3. Treatment of oral candidosis, Aust Dent J, 43:244-9.

Varghese R RM, Masri R, Driscoll CF, Romberg E, 2007. The effect of denture cleansing solutions on the retention of yellow Hader clips: an in vitro study. J Prosthodont, 16:165-71.

You W, Masri R, Romberg E, Driscoll CF, You T, 2011. The effect of denture cleansing solutions on the retention of pink locator attachments after multiple pulls: an in vitro study. J Prosthodont, 20:464-9.

\section{Yazışma Adresi:}

Dr. Haluk Barıș KARA

İstanbul Medipol Üniversitesi

Diş Hekimliği Fakültesi

Protetik Diş Tedavisi AD

Atatürk Bulvarı, No: 27

34083 Unkapanı, Fatih, İstanbul

Tel : 05325043812

E-mail: bkara@medipol.edu.tr 